\title{
Psicología: Subjetividad, Dispositivo E INMANENCIA $^{1}$
}

\section{Psychology: Subjectivity, Device and Immanence}

\author{
Germán Vargas Guillén ${ }^{2}$ \\ Universidad Pedagógica Nacional \\ DOI: $10.17533 /$ udea.rp.v10n1a12
}

Recibido: 2017-08-13 Aceptado: 2017-10-18

\begin{abstract}
Para citar este artículo en APA: Vargas, G. (2018). Psicología: Subjetividad, dispositivo e inmanencia. Revista de Psicología Universidad de Antioquia, 10 (1), 297-323.

DOI: 10.17533/udea.rp.v10n1a12
\end{abstract}

\begin{abstract}
Resumen: Filosóficamente el título psicología designa subjetividad, ésta es lo que es en intersubjetividad. Las sociedades tardocapitalistas reducen la subjetividad a dispositivos de captura, que también son capturados en el enlace entre saber y poder. En este contexto, la individuación implica: fuga, resistencia o anarquía, i.e., volver a la inmanencia desde de la psicología mundana - tanto empírica como experimental—, como la psicología fenomenológica - tanto reflexiva como teórica-.

En la introducción se presenta el problema; en la Sección I se centra la atención en la geografía de la mente, como fue caracterizada por David Hume; en la Sección II se caracteriza el tránsito del dispositivo al disponer; en la Sección III se centra la atención en el contraste entre inmanencia y trascendencia. La conclusión caracteriza la forma como la interacción entre psicología empírica y psicología trascendental se basa en la individuación.
\end{abstract}

Palabras clave: fenomenología, psicología empirica, individuación, trascendencia, biopolitica, psicopolitica.
Abstract: From a philosophical view, Psychology —as discipline — designates subjectivity; subjectivity is only in intersubjectivity. The late capitalism reduces subjectivity to capture dispositive or Apparatus and it is also captured, on the link between knowledge and power. In this context, the individuation involves: scape, resistance or anarchy, i.e., return to immanence from worldly Psychology (both empirical and experimental) to phenomenological Psychology (both reflective and theoretical).

The introduction presents the problem; Section I focuses on the geography of the mind, as it was characterized by David Hume; in section II the transit of the dispositive is characterized to have; Section III focuses on the contrast between immanence and transcendence. Conclusion characterized the form as the interaction between empirical psychology and transcendental psychology is based on individuation.

Keywords: phenomenology, empirical psycho$\operatorname{logy}$, individuation, transcendence, biopolitics, psychopolitics.

1 Artículo derivado de la investigación Bases conceptuales de una psicología de la individuación, Convenio Interinstitucional UdeA-UPN. Códigos: 2017002 (UdeA), UA-UPN 2017 (UPN).

2 Profesor titular Universidad Pedagógica Nacional. Bogotá, Colombia. Postdoctorado Universidad de Texas. Investigación postdoctoral: Meaning Between Phenomenology and Hermeneutics. Correo electrónico: gevargas@pedagogica.edu.co; http:// orcid.org/0000-0001-6156-799X 


\section{Introducción}

Husserl $^{3}$ observó que la temporalidad es la "cruz ancestral" de la psicología descriptiva (Hua. X, 3; v.e., p. 2002, p. 25). Tal vez se puede indicar que la psicología misma es la cruz ancestral de la filosofía. No sólo emerge con Alcmeón de Crotona, sino que llega a su primera sistematización en el De Ánima de Aristóteles.

Incluso en el fragmento sobre las máquinas de los Grundrisse de Marx aparece una vez más esta cruz, ahora bajo la figura emblemática de General Intellect.

La filosofía ha tratado de desembarazarse de la psicología. Hay, en este propósito, dos extremos: tratar de hacer filosofía sin sujeto, proclamar la

3 La "cruz de la psicología" para Husserl a lo largo de su obra se puede evidenciar en un primer momento en la Filosofía de la aritmética, donde intentó fundar la validez de la lógica en las operaciones psíquicas. A esto sucede la sólida objeción de Frege que le lleva a establecer a Husserl, en Investigaciones lógicas, la objetividad de la lógica y la posibilidad de la experiencia fenomenológica de estas estructuras. En 1911 traza, en La filosofia como ciencia rigurosa, la diferencia y complementariedad entre psicología y fenomenología. En 1925 lee las Conferencias de Amsterdam y en 1928 hace las Lecciones de Psicología fenomenológica; en éstas empieza a caracterizar el puesto de la psicología fenomenológica en el conjunto de la fenomenología trascendental. En este año de 1928, igualmente, hace las diferentes versiones del Artículo "Fenomenología" para la Enciclopedia Británica; en estas elaboraciones logra caracterizar las diferencias y sentidos de los títulos: psicología mundana, psicología empírica, psicología experimental, psicología fenomenológica y fenomenología trascendental. Para 1936, de nuevo, elabora la conceptualización de la psicología en la Conferencia titulada La Psicología en la crisis de la humanidad europea.

Cualquier lector de Husserl, sobre todo si inicia su formación en las Investigaciones lógicas, asimila una prevención contra el riesgo del psicologismo y la necesidad de deslindar una y otra vez el campo de la investigación psicológica del campo de la investigación fenomenológica. Sin embargo, investigaciones como: Cosa y espacio; Fantasía, conciencia de imagen y recuerdo; Sintesis pasiva y sintesis activa y, sobre todo, los estudios sobre la temporalidad $(1904-5 ; 1917-8)$ no sólo muestran la continuidad, sino la mutua implicación entre fenomenología y psicología.

Quien se haya prevenido contra la psicología y el psicologismo, por el estudio de las Investigaciones lógicas tiene que llegar a una nueva "conversión de la mirada" para entender cómo de 1928 al final de la vida de Husserl siempre entendió que la psicología fenomenológica está a la base de la fenomenología trascendental.

En el tránsito de 1917 a 1936 la relación subjetividad-temporalidad-individuación, siempre en intersubjetividad, cobra preponderancia en la perspectiva de lo que Husserl llamó fenomenología de la individuación, y, subsidiariamente, con la complementariedad con la psicología fenomenológica de la individuación. Los filósofos quedaron alertados contra la posibilidad de que pensar el conocimiento haga caer en el psicologismo que toma la parte, la operación psíquica, por el todo: la experiencia cognoscitiva; a su vez los psicólogos, entre las críticas al psicologismo, sin recorrer las pruebas antes mencionadas, descalifican la psicología fenomenológica bajo la acusación de psicología reflexiva y en ese sentido "no científica". Acaso el enlace entre ciencias cognitivas y fenomenología empieza parcialmente a superar este doble malentendido que opera como un prejuicio. Es en este terreno en el que se desarrolla el presente estudio. 
muerte del sujeto de Foucault, o la tesis de la existencia de una sociedad sin hombres de Luhmann. Estas versiones se entrelazan, en familiaridad, con el estructuralismo. Y, en el otro extremo, aparecen los enfoques de lo subjetivo como fundamento fundante de toda posibilidad de conocimiento. Este enfoque es el de Husserl, pero en él se entiende que el sujeto es lo que es en intersubjetividad ${ }^{4}$. Lo subjetivo también se ofrece en visiones como las que ofrece el psicoanálisis y todo lo que implica la influencia de éste en movimientos como la Escuela de Frankfurt; acaso un punto intermedio entre la mera objetividad y la absoluta subjetividad sea el índice individuación como la ofrece Simondon (2009), en concreto bajo la figura de la individuación psíquica (cf. Gil, 2018).

De ahí que se pueda observar que, entre el dispositivo que es ahora la subjetividad y la disposición (Vermögens) que es la vida subjetiva, el devenir - que siempre es en relación con el entorno (mundo físico; mundo cultural; otros) temporalmente acontece como el disponer. Este no sólo reconoce el mundo objetivo y la singularidad del yo puedo que funda la experiencia de mundo para cada quien, sino que halla la posibilidad de que cada quien se ponga problemas a sí mismo.

La filosofía contemporánea se mueve entre los extremos de la biopolítica (Foucault, 1974; Virno, 2011) y la psicopolítica (Han, 2015; cf. Vargas y Gil, 2017), pero parece que pensar la individuación en los modos de la fuga, la resistencia o la anarquía, recupera las potencias anímicas y funda una psicología de la individuación: la comprensión de los sujetos, uno a uno, que sólo tienen lugar en el mundo cuando en su devenir transducen y, de retorno, el transducir de los otros configura potenciales (Vermögens) inéditos, más allá de cualquier estructura y de cualquier télos preestablecidos (Vargas, 2014).

$4 \quad$ Mis estudios sobre este particular son: La subjetividad y las perspectivas de la Inteligencia artificial (2003a); La representación computacional de dilemas morales. Investigación fenomenológica de epistemología experimental (2003b); Psicologia y fenomenología trascendentales en el proyecto de la Inteligencia Artificial (2004); Mundo de la vida y fenomenología del lugar (2010); La vía psicológica. La fenomenología y las ciencias de lo artificial (2011a); Formación y mundo de la vida (2012a); La fenomenología y el ideal de la ciencia. En el Centenario del Articulo: La filosofía como ciencia rigurosa (2012b); Stiftung vs. Konstitution en la psicología fenomenológica (2014, Estudio VI). Más recientemente: De la biopolitica a la psicopolitica. Un problema de frontera entre la filosofía y la psicología (2017) y El problema de la constitución histórica del método. Enlace entre filosofía y psicología modernas (2019); estos dos últimos, en coautoría con Lina Marcela Gil. 
Que la subjetividad humana, por definición, sólo deviene con otros, en polis, en societas, implica la indesligabilidad entre filosofía (ética), política y psicología.

La biopolítica ha dado un paso significativo al transformarse en psicopolítica; no se trata sólo de la captura de la vida, sino en particular de la captura de la experiencia psíquica —anímica, espiritual—. En este giro se lleva a su máxima expresión una de las funciones que históricamente se otorgó a la psicología y ésta asumió, a saber: normalizar la subjetividad. En la historia de la locura, en el nacimiento de la prisión, en la emergencia del hospicio, en la aparición de la escuela, en todos estos casos, se acudió a la medicina y a la psicología para establecer los criterios de lo normal y de lo patológico.

Al cabo esta función se ha desligado de la práctica clínica como su principal instrumento o dispositivo. Si se sigue la iluminadora investigación de A. Pentland (2014), se logra establecer cómo la psicología — al lado del diseño, la programación y el servocontrol— se ha convertido en recurso para la captura de la subjetividad mediante estrategias o dispositivos macroestructurales: la moda, la erotización de la cultura, los ideales de salud, las estrategias de control simbólico, la manipulación ideológica; en fin, lo que desde el nazismo se dio en llamar propaganda (Pinzón, 2017).

La psicología, y el psicólogo, progresivamente se ha convertido en medio auxiliar de las estrategias de control simbólico a gran escala. Lo psíquico genera la ilusión de poder experimentar todas las libertades y, sin embargo, sólo se puede hablar de éstas en los marcos de referencia creados por los mass media en versiones cada vez más personalizadas, digitalizadas; es el caso del consumo orientado por la web semántica o web 3. Ejemplos de consumo orientado es el que se ofrece a los usuarios de Netflix, de Amazon, de pornografía; por etnias, grupos etáreos, estratos socioeconómicos, perspectivas ideológicas; en fin, son diseños que capturan la psique en su estructura desiderativa y parecen colmarla; y, sin embargo, cuanta más comodidad —as costumer - experimenta el sujeto, más se lo captura psicopolíticamente.

En el proyecto de globalización — totalidad, totalitarismo; mundialización de los "ciudadanos normales" (ilustrados, bien informados, que se basan en el cálculo racional para la toma de decisiones)—, la psicopolítica se ubica en las 
antípodas de la individuación. La ecuación reza: a mayor masificación, menor individuación; y viceversa.

Por supuesto, al lado de las psicologías puestas al servicio de la masificación y de la sociedad de consumo, hay también la diáspora de las psicologías críticas, de la resistencia, donde cada quien, en su peculiaridad, se ubica como sujeto en posibilidad de fuga ante las diversas formas de captura bio y psicopolitica.

Así, pues, si la subjetividad es uno de los dispositivos en que se anclan tanto las relaciones de poder, o de saber, la filosofía tiene que preguntar a la psicología cómo se posiciona en cuanto dispositivo de subjetividad, y, a su vez, en cuanto captura o desasimiento de ésta.

\section{La geografía de la mente en Hume — como proyecto de psicología del individuo-}

La Fenomenología genética, llevada a cabo con Krisis (Husserl, 1976, Hua. IV), no sólo da cuenta de la matematización de la naturaleza, de la decapitación de la subjetividad, sino también de los límites y posibilidades de la subjetividad en su eclosión moderna —Descartes, Locke, Berkeley, Hume y Kant-. Los límites, en esa eclosión, entre los títulos: yo, cuerpo, cogito y subjetividad, son borrosos. Descartes, además de otras contribuciones, legó el yo al que se ancla la fenomenología, la relación entre experiencia (caracteres) y mente (cera), esto es, el punto de vista según el cual la experiencia activa los procesos mentales. Berkeley situó la relación entre ser y ser percibido (est percibi). Pero es Hume quien ofrece la idea de la mente (psique) como ficción, que despliega el enlace de una sensación con otra por contigüidad, conexidad y relación —esta ficción abre el campo de la ciencia, de la psicología científica, bajo el emblema de una geografía de la mente- Kant ofrece la noción entendimiento en cuya interioridad se posa todo fundamento y proyecto metafísico, reconocimiento —Dios, mundo, alma-.

La geografía de la mente al mismo tiempo permite acercarse a comprender su estructura general, pero ésta se expresa singularmente en cada quien en sus procesos de individuación. 
Del Enquiry de David Hume hay variedad de interpretaciones. La aproximación que se privilegia en este estudio, en especial al examinar la Sección I, es la que ve en esta obra un esbozo de la psicología del individuo —incluso, la aproximación a unas bases de la psicología del individuo - como nota característica del pensamiento moderno. Aunque no se enfatiza en este estudio, es necesario mantener a la vista la concepción liberal y, específicamente, parlamentarista que sostiene Hume. Si en la expresión de Descartes —en que indica que todos los seres humanos tienen la misma proporción de bon sens- se sientan las bases de la democracia; en la perspectiva de Hume se va más allá y se sientan las bases de un pensamiento que se forja sobre la inferencia, la probabilidad y la incertidumbre, como puntos de referencia para reconocer al individuo y su incidencia en la vida común. Obviamente, este giro no llegó a ser posible hasta tanto se pusiera en cuestión la causa y la causalidad; y, más bien, se fundara el conocimiento en el hábito, la costumbre y la creencia.

Para Humes, "La filosofía moral o ciencia de la naturaleza humana" (I, $1,11)$ es el asunto sobre el cual versa la Investigación ${ }^{6}$ sobre el entendimiento humano. ¿Qué es lo que se designa bajo el título "filosofía moral” o "ciencia moral"? Lo primero que llama la atención es que Hume equipara las dos expresiones. Parece que para él no hay diferencia entre una y otra. Quizá, incluso, se pueda colegir que el autor pretende una reducción de la primera a la segunda: se trata de hallar el camino cierto de una ciencia, no en la autorreflexión del cogito — al modo de Descartes—, sino en la experiencia —en la vertiente del empirismo-. El alcance de este proyecto radica en que tiene efectos sobre la politica, el derecho, la milicia y el gobierno (I, 5, 13). Parece que, al menos, éstas son las ramas o disciplinas principales que constituyen el centro de la filosofía moral, de la ciencia de la naturaleza humana. Que la lógica juega un papel aquí, es algo que se puede advertir, pero no es un saber por sí mismo válido; antes bien, éste halla su valor toda vez que permite encaminarse hacia la perfección en el orden de la experiencia o de la acción.

5 En este apartado se recurre a la citación canónica (sección, párrafo, página) de la obra de Hume

6 Enquiry se puede traducir, en efecto, como investigación, pero igualmente como indagación, pesquisa, consulta, estudio, encuesta; e incluso como petición o solicitud. De Salas y Holguín han preferido la palabra investigación para verter esta obra al castellano. No obstante, se debe resaltar que también resultan muy apropiadas las palabras indagación y pesquisa para el título de esta obra. 
En complemento cabe decir: tampoco la política, el derecho, la milicia y el gobierno tienen por sí mismos rigor y fundamento; estas disciplinas tienen que hallarlo en la lógica?.

Hume establece, en la Sección I "De las diferentes clases de filosofía", en un comienzo, que sólo hay dos grandes vertientes, a saber, la "primera [que] considera al hombre como nacido para la acción e influenciado en sus criterios por el gusto y el sentimiento" (I, 1, 11). Esta filosofía toma comportamientos, sentimientos y emociones de los individuos y los compara con grandes ejemplos de la literatura. Su propósito se puede llamar moralista e incluso moralizante.

Según Hume hay "otra clase de filósofos" que "considera al hombre como un ser racional (...) y se esfuerza por formar su entendimiento más que por cultivar sus maneras" (I, 2, 12). Para lograr este propósito, esta filosofía procura establecer "de manera incontrovertible, los fundamentos de la moral de la razón y de la crítica” (íd.). Es ésta la del verdadero filósofo y, al parecer, no reporta utilidad ni placer a la sociedad.

No obstante, Hume argumenta que hay una suerte de justo medio —en el sentido aristotélico del término-, puesto que "El carácter más perfecto pareciera estar entre los dos extremos; (...) capacidad y gusto por los libros (...) y precisión que resultan naturalmente de una correcta filosofía" (I, 4, 14). Es este justo medio el que permite ejecutar la sentencia: "Sé un filósofo, pero en medio de toda tu filosofía, continúa siendo un hombre" (I, 4, 16).

Hume llega a la sentencia sobre el lugar del filósofo, tras la siguiente consideración en voz mayestática, con la que se pronuncia, o bien la filosofía, o bien la naturaleza humana: "Entrégate a tu pasión por la ciencia [knowledge], dice, pero por una ciencia humana, tal que pueda incidir directamente sobre la acción y la sociedad" $(\mathrm{I}, 4,15)^{8}$. De este modo establece, incontestable-

7 Bajo el título lógica no sólo se estudian las leyes del pensamiento, por igual se hace alusión a los fundamentos y operaciones del conocimiento (mind, knowledge) — - y, como se verá más adelante, "la voluntad y el entendimiento, la imaginación y las pasiones" (I, 8, 22)-.

8 La edición inglesa y la traducción de Jaime de Salas Ortueta conservan la anterior cita en comillas, la edición de Magdalena Holguín, no. Es razonable la versión de Holguín, toda vez que en el texto la expresión y el párrafo se muestra cómo es "la naturaleza humana" la que ha "señalado un tipo de vida variado como el más apropiado para la raza humana” $(\mathrm{I}, 4,15)$. 
mente, un vínculo entre la filosofía especulativa y la filosofía práctica, entre el conocimiento y la acción, entre los fundamentos y los ejemplos.

El justo medio, metodológicamente, equivale a la relación entre el anatomista y el pintor; el geógrafo del entendimiento — que también, en resultas, se puede caracterizar como psicólogo — opera como el anatomista:

El anatomista nos presenta los objetos más horribles y desagradables, pero su ciencia es de gran utilidad para el pintor incluso cuando esboza una Venus o una Helena. Mientras que éste último emplea los colores más ricos de su paleta para dar a sus figuras un aspecto grácil y atrayente, debe sin embargo atender a la estructura interna del cuerpo humano, la posición de los músculos, la estructura de los huesos, el uso y aspecto de toda parte u órgano. La precisión es, en todos los casos, ventajosa para la belleza, tanto como el justo razonamiento para el sentimiento delicado. En vano exaltaríamos uno de ellos si desdeńamos el otro (I, 5, 17).

¿Cómo, pues, diferenciar las bases, incluso, biológicas del comportamiento de las interacciones culturales con el entorno, su mutua configuración? Según esta perspectiva, se podrá poner el acento en alguno de los polos, pero se pierde la comprensión, el sentido, si la investigación se reduce a uno de ellos.

$\mathrm{Al}$ amparo "De las diferentes clases de filosofía", incluso con la valoración de la primera como "fácil" y la segunda como "abstrusa" — condición ésta para que aquella sea rigurosa y se acerque directamente al público-, en ese justo medio se le da por tarea a la filosofía moral hacer que: "El político [adquiera] una mayor visión y sutileza en la división y equilibrio del poder; el abogado un mejor método y más refinados principios en sus razonamientos; el militar una mayor disciplina y cautela en sus planes y operaciones" (I, 5, 17). Ésta, pues, no es sólo una filosofía especulativa — aun cuando tiene tal virtud como uno de sus momentos, a saber, en el que establece los fundamentos-, sino que es, estrictamente, filosofía práctica. De hecho, esta última desemboca en la políti$\mathrm{ca}$ - que esta sea liberal y parlamentaria, no es asunto aquí, pero se evidencia en los Ensayos morales, politicos y literarios (I, VI, pp. 74-77)—, puesto que también esta filosofía lleva a "La mayor estabilidad de los modernos gobiernos en relación con los antiguos" (Enquiry, I, 5, 17)

Esta tarea, con el ejercicio del "genio filosófico" ["the spirit of Philosophy"] convierte al investigador en "benefactor de la humanidad" (I, 6, 18) —algo 
así como "funcionario de la humanidad", según palabras de Husserl-. En este propósito, se trata de que el filósofo descubra la "legítima providencia de la razón humana" (I, 7, 19); así Hume anticipa, se puede decir, una crítica de la razón pura. Para ello se propone un método que libere "de inmediato [al] conocimiento de (...) abstrusas cuestiones", precisamente, por medio de un proceso que permita "investigar con seriedad la naturaleza del entendimiento humano" para poderlo "mostrar, a partir de un análisis preciso de sus facultades y capacidad” (I, 7, 20). Según Hume, este es el contenido de esta ciencia o geografia. En este contexto, Hume llama metafisica a "todo razonamiento profundo" (I, 5, 16). Ésta se debe "cultivar" y se debe tomar como "la verdadera" (I, 7, 20) cuando investiga "la naturaleza del entendimiento humano" (íd.); en cambio, es "falsa y adulterada", debe "superarse", cuando se sume en "la jerga metafísica", se mezcla "con supersticiones populares", en último término, cuando "comunica una apariencia de ciencia y sabiduría" (íd.).

¿Dónde encalla, o puede encallar, este proyecto? En síntesis,

[en] el escrutinio preciso de los poderes y facultades de la naturaleza humana (...). Respecto de las operaciones de la mente (...), no obstante sernos íntimamente presentes, cuando se constituyen en objeto de reflexión parecen envueltos en mayor oscuridad. (...) los objetos son demasiado sutiles para conservar durante mucho tiempo el mismo aspecto o situación y deben ser aprehendidos por medio de una intuición superior, derivada de la naturaleza y perfeccionada por el hábito y la reflexión" (I, 8, 20-21).

En suma, el conocimiento de las operaciones de la mente es difícil porque al conocer, lo conocido cambia por el acto o proceso de conocimiento: quien conoce es a su vez objeto de la investigación, hay una inseparabilidad entre el sujeto y el objeto de conocimiento. Esto es lo que hace problemática la introspección como método.

Y, sin embargo, es preciso observar que los poderes de la mente se diferencian entre sí a raíz del tipo de percepción del cual derivan. Así, éstos se pueden distinguir por la reflexión; esta reflexión se expresa en proposiciones; las proposiciones pueden ser contrastadas; es la contrastación la que permite establecer si las proposiciones sobre los poderes de la mente son: verdaderas 
o falsas (I, 8, 20-21). Con esto hay no sólo un método de observación, sino de contrastación que se separa de la autoobservación, de la autorreflexión, de la autoconciencia como diversas formas de captación del cogito a través de la introspección.

La geografía del entendimiento caracteriza diversas regiones o distritos: "la voluntad y el entendimiento, la imaginación y las pasiones" (I, 8, 22). La filosofía tiene una tarea que se puede considerar valiosa, a saber, describir "las partes de la mente" (íd.). De este modo Hume parece renovar — a través de la experiencia- el lema del Oráculo de Delfos: «iConócete a ti mismo!». Este objetivo sólo se puede realizar si se da un paso previo: conocer los poderes y facultades de la mente. Según Hume, este programa exige "llevar sus investigaciones" hasta "descubrir los resortes y principios que mueven la mente en sus operaciones" (I, 9, 22). Ahora bien, todo ello tendría que dar con "investigaciones acerca de la mente y su economía (mental powers and economy)" (I, 9, 23).

\section{La filosofía: entre el dispositivo y el disponer}

En este parágrafo se sostiene la tesis según la cual la filosofía y la política son indesligables. Esta tesis, a su vez, implica que la filosofía, como dispositivo de Saber, siempre está enlazada con los dispositivos de Poder y Subjetividad; no obstante, el sujeto filosófico como sujeto político no sólo se subjetiva, sino que también se individúa —no sólo como proceso del devenir, sino como acción del disponer-. Para mostrar esta tesis, el parágrafo se desarrolla en tres momentos. En el primero, se hace una reflexión en torno a la concepción que tienen Deleuze y Guattari sobre la filosofía para mirar la importancia de la desterritorialización y la reterritorialización que dan cabida a la política. En el segundo, se expone cómo el dispositivo hace parte de la reflexión filosófica y es el lugar tanto de la subjetivación como de la individuación del sujeto. Finalmente, se retoma de nuevo la pregunta de si la filosofía es desligable o indesligable de la política a la luz de la noción de dispositivo, para concluir que todo sistema filosófico implica una posición política y toda posición política 
requiere una posición filosófica. Una y otra cuestión remiten al sujeto a la vida subjetiva y sus posibilidades de fuga, de ponerse en las márgenes, en fin, de producir un movimiento anárquico. Este es "cosa misma" de la psicología, en especial de la psicología de la individuación.

La introducción a la filosofía y el trasegar dentro de ella, carga a cuestas con la pregunta: ¿Qué es esta disciplina?, como primera cuestión. La respuesta a este interrogante es problemática y variable; en cambio, reconocer temas o problemas como filosóficos es algo relativamente sencillo. Así, por ejemplo, estudiar las preguntas relativas al Ser, al conocer, al actuar, al convivir, al pensar, entre otros, son asuntos que fácilmente se reconocen como relativos a la filosofía en cuanto disciplina. Al lado de estos asuntos están las preguntas por el origen y por el fin; son las cuestiones que tocan con la existencia histórica de los individuos, las comunidades y las culturas.

Autores como Han (2012, 2015), Virno (2003, 2011), Lazzarato (2006), Agamben (2014), ponen esta constelación de preguntas en el circuito que transita de la bio a la psicopolítica. Todos ellos han mostrado una suerte de indesligabilidad entre la filosofía y el mundo de la vida político, comunicacional, mediático, en la globalización tardía de Occidente (cf. Vargas, 2011b; Gil, 2016). Éste es el entorno de la experiencia psíquica, de cada quien qua sujeto y como parte del horizonte intersubjetivo. En este parágrafo se pone en estudio el alcance de la conexión sugerida en esa tradición al amparo de los títulos dispositivo y disponer (cf. Vargas, 1999). Como se verá al final del parágrafo, la vita activa implica la constitución del sujeto político como orientación estructural del pensamiento de orden filosófico.

Deleuze, en asocio con Guattari (1993), estudió la pregunta ¿Qué es filosofía? en el libro del mismo nombre. Acaso en la conspicua tradición hegeliana, los autores observan cómo la tarea de la filosofía es, en síntesis, la elaboración de conceptos. Desde luego, "todo concepto remite a un problema, a unos problemas sin los cuales carecería de sentido, y que a su vez sólo pueden ser despejados o comprendidos en la medida que se vayan solucionando" 
(1993, p. 22). Esta praxis, por así llamarla, tiende, a su vez, a lo que los autores denominan la "pedagogía del concepto" (p. 22). Así, "todo concepto tiene su historia" (p. 23). Según los autores, "las relaciones en el concepto [...] son [...] sólo de ordenación, [...] meras variaciones ordenadas en función de su proximidad. Son procesuales" (p. 26). La filosofía, pues, se orienta a la conceptualización del mundo, el cual es cambiante; también los conceptos son cambiantes, si se quiere, epocales.

Para los autores, "encontramos por doquier el [...] estatuto pedagógico del concepto" (p. 37): con él se quiere mostrar o enseñar algo, conducir en variedad de direcciones. Entonces, el concepto mismo, hijo de la tradición, es un campo agonal, de disputa, creado por él mismo y por la interacción que tienen con él quienes lo piensan, según la época y el contexto de referencia al cual se hace alusión con éste.

En este sentido, cabe entonces observar cómo "si la filosofía comienza con la creación de los conceptos, el plano de inmanencia tiene que ser considerado prefilosófico. Se lo presupone [...] del modo que los remiten a una comprensión no conceptual” (p. 44). Es, digámoslo, una paradoja: por un lado, la filosofía vive del concepto; pero, por el otro, no se trata de un ejercicio de palabras autoreferenciales, sino que ellas, cuando tienen el carácter de conceptos, aluden —digámoslo así— al mundo. Según esta perspectiva: "el plano de inmanencia [...] constituye el suelo absoluto de la filosofía, su Tierra o su desterritorialización, su fundación, sobre los que crea conceptos" (p. 45). Es, pues, en la vida — nuda, si se quiere, salvaje - sobre la que se asienta el pensar, a la que remite el concepto, sobre la cual se opera desde la conceptualidad constituida y desplegada. Más aún, "el plano de inmanencia es como una sección de caos, y actúa como un tamiz" (p. 46). Como caos se refiere a la "ausencia de determinaciones" (p. 47). En algún sentido, se trata de pensar lo impensado. El concepto viene a surtir un efecto sobre el caos. Frente a éste, "el problema de la filosofía [es] adquirir una consistencia sin perder el infinito en el que el pensamiento se sumerge" (p. 47). Es, pues, tarea de la filosofía atenerse a lo que hay; y, desde allí, erigir una comprensión, un sentido de mundo. Se entiende, entonces, por qué "el plano de inmanencia toma prestadas del caos determinaciones que convierte en movimientos infinitos o en sus rasgos dia- 
gramáticos" (p. 53); así, quiérase o no, la filosofía es un potencial demiúrgico: introduce un orden en el caos, en medio de él. Ahora bien, que esta operación demiúrgica pueda reclamarse única o exclusivamente válida, resulta fuera del propósito mismo de la filosofía. Más bien, una pretensión tal transforma el pensamiento en doctrina, en dogma, en ideología.

Un planteamiento de los autores exige un registro y una reflexión:

\begin{abstract}
Llevando las cosas al límite, ¿̇no resulta que cada gran filósofo establece un plano de inmanencia nuevo, aporta una materia del ser nueva y erige una imagen del pensamiento nueva, hasta el punto de que no habría dos filósofos sobre el mismo plano? (p. 54).
\end{abstract}

Siguiendo a Deleuze y Guattari se puede reiterar el dictum según el cual, al filosofar, de lo que se trata es de «ir a las cosas mismas!». Esa cosa misma, según ellos, es el caos; una suerte de magma original, un desorden. La operación demiúrgica del concepto crea un orden, un mundo, un cosmos. ¿Es universalmente entendido ese dispositivo conceptual? $\mathrm{O}$, antes bien, ¿se trata de un dispositivo universalmente entendible? Como quiera que se enfrenten esas cuestiones, "se plantean una multitud de problemas que se refieren tanto a la filosofía como a la historia de la filosofía” (p. 60). Sólo que cada uno de los conceptos se despliega en el que se puede, según esta perspectiva, denominar como "personaje conceptual" (p. 71). Éste no sólo puede expresar el punto de vista del filósofo, también su opuesto; se despliega, así, una confrontación entre estos rasgos a lo largo de la obra de un filósofo (p. 75). En este despliegue "el personaje conceptual interviene [...] entre el caos y los rasgos diagramáticos del plano de inmanencia. [...] Los personajes conceptuales constituyen puntos de vista según los cuales unos planos de inmanencia se distinguen o se parecen [...]" (p. 77).

La filosofía exige una relación —arcana, venida de muy lejos; actual, lanzada a un futuro incierto - con dos componentes, a saber, "el territorio y la tierra" (p. 86); se trata de "dos zonas de indiscernibilidad, la desterritorialización (del territorio a la tierra) y la reterritorialización (de la tierra al territorio)” (p. 86). La filosofía, aunque cuenta con la aparatosa caída de Tales de Mileto, a quien una vieja increpa diciéndole, más o menos, “AAh! Tú que presumes 
conocer los cielos. ¡Ni siquiera sabes por dónde caminas!”, según nos lo ha informado Diógenes Laercio (1995); la filosofía es un estar atado, asido a la tierra: magma o caos original; sólo que se transmuta en concepto, como si se hechizara la cantidad en o con un arte poético. "En este punto es donde aparece una diferencia según que la desterritorialización relativa sea de inmanencia o de trascendencia" (Deleuze y Guattari, 1993, p. 90); que se parte del caos en dirección del concepto o que, dado el concepto, se exige retorno a la tierra: de esto es de lo que se trata. Así, se puede establecer como máxima: no hay ninguna práctica filosófica-conceptual que no considere la mundanalidad y la territorialidad de la experiencia; no hay ninguna conceptualidad-filosófica que no retorne al suelo original de la tierra como su único lugar de validación, de garantía de su sentido.

Aquí es donde la filosofía se entrelaza con la política. Para Deleuze y Guattari: "La inmensa desterritorialización relativa del capitalismo mundial necesita reterritorializarse en el Estado nacional moderno, que encuentra una resolución en la democracia, nueva sociedad de "hermanos», versión capitalista de la sociedad de los amigos" (p. 99). Los autores llegan a este punto aludiendo al concepto de "hogar" que introdujo Husserl (en Krisis, Hua. XXIX,1993), esto es, agrupamiento "territorial" y "un parentesco familiar" (p. 99).

2

Según Deleuze (1990) los dispositivos son, para Foucault, tres: Saber, Poder y Subjetividad. Aparecen, en primer término, como (1) "curvas de visibilidad" y (2) como "curvas de enunciación" (1990, p. 155). Sólo "en tercer lugar, un dispositivo implica líneas de fuerza" (p. 15). Estos tres entramados tienen su correlato, a su vez, con Saber, Poder y Subjetividad. Ahora bien, más que darse o existir el sujeto, lo que acontece es que deviene "una línea de subjetivación" que tiene el carácter de "producción de subjetividad en un dispositivo" (p. 157). Ésta es una suerte de fuga o escape en el seno mismo del dispositivo: "no es ni saber ni un poder. Es un proceso de individuación” (p. 157, cursiva ajena al texto). En este contexto de referencia se subjetivizan "tanto los nobles (...) como los excluidos" (p. 157). Se produce, pues, una panoplia — se puede lla- 
mar, incluso, diáspora - de "formaciones subjetivas de dispositivos móviles" (p. 157). Se trata de variedades de subjetividad que "se escapan de los poderes y los saberes de un dispositivo para colocarse en los poderes y saberes de otro, en otras formas por nacer" (p. 157). Aquí no se discute si hay un juego libre de la voluntad o, antes bien, se trata de un mero despliegue de la determinación. Parece, en todo caso, que se trata de esto último, del fluir de la inmanencia.

El problema con el cual parece enfrentarse esta "comprensión" —o si se quiere "teoría” - es que no hay manera de delimitar qué es un dispositivo, dónde están tanto su límite como su "afuera". Todo parece quedar "adentro" de algún presunto dispositivo (p. 159). Así, todo parece derivar en una "estética intrínseca de los modos de existencia como última dimensión de los dispositivos" (p. 159). Al cabo, "lo que cuenta es la novedad del régimen, no la originalidad de la enunciación” (p. 159).

En esta perspectiva, lo que vale subrayar es que "pertenecemos a ciertos dispositivos y obramos en ellos" (p. 159). Todo esto desemboca en el archivo: registro de devenir y anuncio - apertura, si se quiere- del acontecimiento (Vargas, 2011b, Estudio IV).

Aquí se desenvuelve el juego entre sedimentación y creatividad. "No somos ya griegos, ni siquiera cristianos" (p. 161).

¿Qué alcance tiene, en este contexto, el título individuación? Por supuesto, se emparenta, pero también se diferencia de subjetivación. Uno y otro proceso tienen que ver con el sujeto. Mientras la subjetivación captura —o sujeta—, la individuación es efecto del conatus. En la individuación el sujeto procede al desasimiento —incluso se puede decir a la des-subjetivación- Cuando el sujeto "no cabe", "no puede", "no opera" dentro de los límites del dispositivo, entonces lo desborda. No obstante, esta fuga en la que se traspasan los límites del dispositivo no acontece como decisión de la voluntad — consciente, racional, deliberada - Simplemente deviene. Por eso, la individuación — que deviene, desata, desborda en la fuga- es inmanencia pura, vida salvaje, protoimpulsividad. Esta fuga, empero, no es una actuación irracional: obedece a la ley de estructura. No se obra una razón subjetiva; antes bien, se opera una razón de... o en la estructura: se estructura, acontece, deviene. Y, sin embargo, se crea. 
Vamos ahora con la cuestión que alienta este parágrafo: ¿¿Son desligables o indesligables filosofía y política? Si se toma en consideración una primera manera de caracterizar uno y otro campo, cabe hablar de ellos como dispositivos. Uno opera sobre el otro y viceversa. El primero se puede caracterizar como dispositivo de Saber, el segundo como dispositivo de Poder. Uno y otro se entrelazan a través de un tercero, esto es, el de Subjetivación. No obstante, el enlace paradójicamente resulta como efecto de la interacción del primero y el segundo dispositivo; y, sin embargo, para hacer más compleja la relación entre ellos: la Subjetividad se fuga o se desliga o se desase en cuanto se individúa, bien como en un pasaje de un dispositivo a otro; bien como resignificación o reconfiguración de un dispositivo en otro - sea que el de Poder configure otra expresión de Poder, sea que el de Saber configure otro Saber, sea que una forma de Subjetividad devenga en otra-.

Ahora bien, se observa cómo los dispositivos pueden, sí, estar uno — si se quiere- adyacente al otro o a los otros, en interacción con otro o con los otros; y pese a sus límites difusos: se puede establecer un borde o un límite que permite reconocer que se está en su interior o en su exterior, en un puente o en una frontera entre ellos. ¿Cómo, entonces, acontecen estas relaciones? Los dispositivos se condicionan mutuamente, pero, de igual modo, se potencian unos a otros: el Poder se dilucida y expresa su gramática, justamente, mediante el Saber; el Saber se configura en sus posibilidades efectuales a partir de su relación con el Poder. ¿Qué decir, entonces, en estas interacciones, en relación con la Subjetividad? Cierto, ésta es efectuada —esto es, es efecto— de la interacción de las estructuras Saber-Poder; pero, al mismo tiempo, la Subjetividad pone en ejecución los potenciales de tales estructuras: no sólo las soporta en su devenir, sino que las pone en los límites de su despliegue hasta llegar a configurar otras expresiones, sea que en unos casos se acentúe uno de los polos (Saber-Poder) o que los confronte o que les genere un rendimiento que pone en cuestión su carácter de status quo.

Agamben (2014) "literalmente" llamó "dispositivo [a] cualquier cosa que tenga de algún modo la capacidad de capturar, orientar, determinar, intercep- 
tar, modelar, controlar y asegurar los gestos, las conductas, las opiniones y los discursos de los seres vivientes" (p. 3). Relacionó el dispositivo con la Trinidad (Padre — que tal vez se pueda correlacionar con Poder-, Hijo — que tal vez evoca la Subjetividad - y Espíritu Santo — que, a su manera, da cuenta del Saber-) (p. 3). Este modelo teológico no separa irreconciliablemente las tres personas, pero a cada una de ellas le compete una acción que le es propia y singular a su naturaleza, sin que por eso se pierda su entidad.

La política tiene que ver con la manera como operan los dispositivos —acaso sea imperativo el uso del plural, en este caso- de Poder. Desde luego, sólo una faceta de este dispositivo se expresa como gobierno, como gubernamentalidad, como gobernanza. Más allá de esta manifestación hay expresiones como las estructuras de la participación, los mecanismos de control ciudadano, las formas de la policía, de la higiene, de la libre movilización, de los derechos humanos. El Poder no es un dispositivo homogéneo ni unilateral. Si bien hay formas de control, también hay formas de resistencia, de fuga, de —se puede decir en una sola palabra- desgobierno.

Ahora bien, hay códigos, academias, formas de producción de conocimiento (normales, paradigmáticas), formas de medición de la productividad científica y tecnológica, establecimientos de producción y reproducción simbólica: las universidades, las Escuelas Normales, los colegios, las escuelas, los institutos técnicos; las editoriales, las revistas, las ediciones digitales, las conferencias, las clases, los seminarios, los talleres. Son las formas que se sedimentan en el modo de archivo. Y, sin embargo, la irrupción de un acontecimiento de pensamiento — de creación poética, de ciencia- exige una anomalía, una ruptura, una resignificación (cf. Vargas y Gil, 2013).

Cierto, se pueden operar cambios discursivos tanto en el orden del Poder como en el del Saber. Pese a ello, la cualidad de dispositivo exige que se opere una materialización en el modo de régimen. Éste designa no sólo una positividad discursiva. También trae consigo: prácticas, formas de vida, disciplinas, formas de registro, de movimiento, de gestualidad, de acción.

Los regímenes tocan con la Subjetividad: no sólo la producen, sino que también propician un espacio para las grietas donde se instala la individuación. Estas grietas son las márgenes, los intersticios. Se los puede ver operar en el 
lenguaje, en la positividad de la legislación, en las conversaciones alternativas de los sujetos instalados en diversas localizaciones. Por esas grietas se produce la fuga, la resistencia. Al cabo, la emergencia de lo inédito; en fin, el acontecimiento.

En su manera de apelar a la Trinidad, Agamben indica que "tenemos [...] dos grandes clases, los seres vivientes o las sustancias y los dispositivos. Y, entre los dos, como un tercero, los sujetos" (p. 4). Los sujetos ponen en movimiento las substancias y los dispositivos. En síntesis, es el sujeto el que puede, al cabo, disponer - bajo este índice se resaltan funciones tales como: anteponer, proponer, predisponer, reponer, componer-. Según la línea que viene de Foucault, Deleuze y Agamben —acaso con base en la concepción de Simondon; y aún más remotamente en Scoto y Occam- la individuación es un devenir que no cuenta con potenciales anímicos tales como la voluntad y la libertad. Enraizado en esta misma tradición —Descartes, Leibniz, Kant, Husserl, Heideggerestas dos últimas variables entran en juego, entonces no es sólo cuestión de devenir, sino de decidir.

El disponer tiene la fuerza de la decisión. Ésta no descalifica el devenir, sólo que lo transmuta en motivación. Es en esta donde tiene sentido, dentro de márgenes — que también son condicionamientos—, las posibilidades del sujeto. Ser-sujeto, entonces, tiene que ver con Querer y Poder-ser; así mismo, tiene que ver con la voluntad de Saber. Más, entonces, que dispositivos — que lo son-, también se puede hacer alusión al disponer. Se trata del compromiso que puede tomar cada quien como punto bascular de la configuración del mundo, del sentido del mundo. Lo que también se puede llamar sujeto político.

\section{Inmanencia, personalidades de orden superior y nor- mas trascendentales de la razón}

Por personalidades de orden superior (POS) Husserl (1987) entiende aquella persona que somos, que no se agota en nosotros y que nosotros enriquecemos con nuestra pertenencia a ella. Sea el caso, la familia, el barrio, la escuela, la iglesia, la ciudad, la nación, el Estado, la comunidad de las naciones, las 
organizaciones internacionales de Estados. Así, pongamos por caso, uno es plenamente perteneciente a su familia, la idea y la práctica de esa familia no se agota en uno, uno enriquece con su pertenencia la familia que le es propia. Esto no implica, ni mucho menos, un sistema de determinación; antes bien, cada $P O S$ es un entorno de individuación que le sirve de motivación.

La familia de uno — para este ejemplo, la vargasguillenidad: mi familiaforma parte de una familia más amplia —los vargaslópez, los guillenpatiño; los vargasrestrepo; los rodríguezvargas, los mendozavargas; los guilléngarcía, guillénpalacio; etc.- - La vargasidad no se agota ni en mi familia, ni en ninguna otra de las combinaciones mencionadas, ni mucho menos en mi persona. Pertenezco a ella, ella me posibilita, pero no me determina; ella se realiza en todos y cada uno de los miembros que pertenecemos a ella. La POS-familia es, nada más y nada menos, entorno de individuación, ámbito de la motivación.

Mi familia, particular y concreta, no sólo se relaciona con las familias con vínculo de consanguinidad, sino también de afinidad civil. Más allá, mis vecinos conforman familias. Al cabo, tenemos que hacer, aunque sea sólo por solidaridad mecánica —no orgánica, ni las demás formas de solidaridad-, por fuerza, una unidad: unidad residencial, unidad de vecinos, junta de acción local, junta de acción comunal, etc. Aprendemos las normas inmanentes a nuestra familia. También aprendemos las normas inmanentes de la relación entre familias en una unidad residencial, etc. Nos respetan, los respetamos; se hacen respetar, nos hacemos respetar.

Podemos mirar cómo se transita de la inmanencia de las normas de convivencia de una familia a un barrio; si pertenecemos a una escuela o a una iglesia, progresivamente aprendemos las normas que les son inmanentes a ellas. Lo mismo, aunque son más abstractas, vamos aprendiendo las normas de convivencia ciudadana, nacional, internacional. Estas leyes, en su inmanencia, se van cambiando. En su historicidad, inmanentemente, devienen. Son ajustadas a la inmanencia de las circunstancias. Se "negocian" cuando son inadecuadas a los intereses de uno o de muchos de los miembros de esa POS.

¿Dónde, pues, está la trascendencia de estas normas de la razón? En resumen, cuando se objetivan y se pretende que valen para uno y valen para todos. Son trascendentales a los sujetos, son inmanentes a una cultura, a una 
sociedad; al devenir histórico de una y otra. Su corregibilidad es parte de su inmanencia.

¿Puede haber inmanencia de las normas e, incluso, son $P O S$ pongamos por caso, una organización criminal, una banda, una barra brava? En resumidas cuentas, sí. Las normas de ética de los matones, de los mafiosos, de los vándalos, etc., no sólo son inmanentes a la "organización" respectiva, sino también "trascendentales" a los sujetos que adhieren a una y otras; individúan y transindividúan. Los matones, los santos, los artistas, los filósofos, los empleados: se individúan y transindividúan. Sólo en el cotejo de las normas y, si se quiere, de la universalidad de una $P O S$ con respecto a otra aparece su insuficiencia, su inadecuación, su impropiedad.

Las normas trascendentales de la razón son inmanentes a las POS y su validez es relativa al contexto de referencia, dentro del cual se ponen como referente. Una psicología de la individuación se ocupa de ver cómo se acopla o resuelve el conflicto, uno a uno, de cada individuo con respecto a la POS que le sirve de entorno. También los matones o los mafiosos, como los artistas o los santos, tienen que resolver la tensión individuación-transindividuación; aspiran a una "vida feliz" e incluso "beata".

Uno de los principales dispositivos de captura de la subjetividad es la psicología como disciplina -incluso, como práctica- y como ciencia. Si se mantiene la diferencia entre Poder, Saber y Subjetividad, se puede decir que la judicialización de la conducta es del orden del Poder; comprender la conducta del orden de la subjetividad; dar con la autocomprensión de sí y del mundo es del orden del Saber. El dispositivo Subjetividad aparece más allá de toda judicialización y toda teorización: volver sobre cada quien como un haz de potenciales (Vermögens) que también se pueden llamar disposiciones. En la terapéutica el psicólogo reconoce los procesos y estrategias de individuación que vive cada quien. El sí mismo, el self, se concreta, se constituye con su entorno y es función de la terapéutica clarificar las relaciones de alteridad. No es un 
problema del orden moral o científico, sino de las posibilidades que tiene el ser de transducir, en mayor o menor medida, en su entorno.

Las POS son un referente para la acción, un horizonte de individuación psíquica y colectiva; al ser pensadas, al volver la mirada sobre los vínculos, toman valor para uno y para todos. Una psicología de la individuación advierte las tensiones entre el individuo y el entorno y favorece los potenciales transindividuales.

\section{Conclusión}

¿Qué papel juegan las normas empíricas en la interacción de los sujetos y cuál es el valor de las normas ideales o trascendentales de la razón? Husserl distinguió entre psicología empirica — mundana, experimental- y psicología trascendental - fenomenológica- En la primera de lo que se trata es de caracterizar la génesis de las operaciones psíquicas, esto es, la configuración del sentido en la experiencia de sujetos singulares; pero, a su vez, estableció cómo "nacidas en personas singulares las ideas albergan infinitudes intencionales" (1976, Hua. VI, pp. 314-348). En último término las normas empíricas valen para uno y para el círculo de los que comparten una unidad fáctica común: familia, clan, tribu, etc; en cambio, las segundas valen para uno y para todos con independencia del contexto histórico, social, familiar, tribal.

La detrascendentalización de la razón alcanza las normas empíricas de la razón, pero la psicología fenomenológica y la fenomenología trascendental se hallan frente a normas ideales. Aquéllas sólo llegan a plena validez a partir de éstas, éstas se convierten en mundo de la vida sólo a través de aquéllas (cf. Guerrero, 2017).

Si el disponer es una guía para comprender y realizar la individuación, es porque acude a la configuración de normas personales y colectivas, fácticamente desenvueltas en el devenir; pero, éstas son revaluadas o reorientadas al amparo de la máxima universalidad, philosophia perennis que permite hallar horizontes que traspasan la facticidad del darse y configuran un horizonte de humanidad posible. 
Si, como ya se dijo, se individúa tanto el matón como el santo, lo hacen al trasponer su individuación en transindividuación; son normas que valen para uno y en principio para todos. Sólo que este todos no es un universal afirmativo, sino un singular afirmativo (algunos); esto es, vale para todos aquellos que comparten una unidad fáctica de representación y valoración de mundo.

Pero el bien del santo 9 o el matón se relativiza y se reorienta cuando se da el paso del singular afirmativo — que sólo tiene el alcance de: "algunos" — al universal afirmativo — todos en todas las circunstancias, en todas las épocas de la historia-.

¿Puede la psicología transitar de la subjetivación, individualmente considerada, a la constitución intersubjetiva que se individúa transindividuando? Sí, y sólo sí, la psicología pasa de la empiría al eidos, del uno a uno a las estructuras universales; en último término, si trasmuta la psicología empírica en psicología trascendental fenomenológica.

Fink mostró —en la VI Meditación cartesiana — cómo el fenomenologizar, a saber, el hacer emerger la visibilidad de los fenómenos es común a los sujetos en actitud natural y en actitud trascendental. Esto implica, según las palabras de Husserl, dar el paso de la génesis al origen, de la psicología descriptiva a la fenomenología trascendental. ¿Cómo es esta psicología?, es la tarea que abarca la investigación fenomenológica sobre la psicología. Cómo se enlaza

9 Cada una de las dimensiones de la psicología tienen su valor intrínseco. La psicología empírica se ocupa de la génesis de la sensibilidad, la afecto-emotividad, el mundo de la vida subjetivamente dado. La psicología trascendental fenomenológica tematiza las estructuras — temporalidad, espacialidad, subjetividad, intersubjetividad - desde normas trascendentales de la razón: horizontes de sentido que valen para uno y valen para todos. La psicología de la individuación es un vaivén de un polo a otro que enriquece a ambos; se ocupa de los procesos que subyacen a la constitución del psiquismo: afecto-emotividad, senso-percepción, resolución de problemas mediante la acción, al tiempo que propone horizontes de sentido desde la dimensión transindividual: lo psíquico y lo colectivo se despliegan simultáneamente en el sistema indisoluble entre individuo y entorno. Si un proceso de individuación empobrece, bien sea el entorno o el mundo subjetivo, individual, se dice que no es transductivo, no favorece los potenciales de unos y otros. La voz de Teresa de Ávila: "un santo triste es un triste santo" expresa la disarmonía de la experiencia individual, aun en el cumplimiento de normas trascendentales de la razón. La alegría sería el sentimiento que exprese la transdividuación. El psicólogo fenomenólogo no se ocupa del cómo hallar esa armonía individuo-entorno o cómo disponer de la intervención, uno a uno, para lograrlo, pero sí aclara por la vía fenomenológica las variaciones del sentido de mundo y tematiza las estructuras de la constitución de lo somatopsíquico, sin recurrir necesariamente a la génesis empírica de estos procesos. (Agradezco esta nota, como síntesis, a discusiones sostenidas con la prof. dra. Lina Marcela Gil, en desarrollo del Proyecto Bases conceptuales de una psicología de la individuación). 
la psicología fenomenológica con los datos de las ciencias — neurociencias, ciencias cognitivas, sociología, etc.- es materia de la investigación contemporánea (Zahavi y Gallagher [2014], Gallagher [2006], Depraz [2014]; Lingins [1983], Gendlin [1978/79]; Botero [2009, 2010]).

Según nuestro punto de vista el enlace entre psicología científica — naturalización (Hernández, 2018) - y psicología fenomenológica exige el paso por la dimensión idiosincrásica; a saber, cómo se individúan los sujetos en sus estructuras neuronales y cognitivas es tan relevante como los procesos de individuación en cada sociedad y en cada cultura (Vargas, 2018).

Y, sin embargo, más allá de cualquier dato científico, ofrecido por la génesis de la constitución de sentido en los sujetos singulares, hay estructuras que valen para uno y valen para todos — temporalidad, espacialidad, intersubjetividad, historicidad, etc. (Hua. XXIX, \$34)—; esta es la materia de investigación de la psicología fenomenológica.

Los Manuscritos de Bernau (1917-1918) en su Sección VI fueron dedicados por Husserl a la fenomenología de la individuación. Que todo proceso de individuación es temporal, y a su vez es vivido singularmente por cada quien, tiene su correlato en el hecho de que las estructuras temporales de la individuación psíquica tienen una estructura empírica — sujeto por sujeto-y trascendental — válidas para uno y válidas para todos-. Nuestra hipótesis es que la captura contemporánea, tanto de subjetividad como de individuación, es lograda por la primacía de la psicología empírica sobre la trascendental; y, en consecuencia, la puesta en fuga de este imperativo cientificista o naturalista se logra al amparo de la dilucidación de las estructuras trascendentales de la vida psíquica en su configuración intersubjetiva. 


\section{REFERENCIAS}

Agamben, G. (2014). Qué es un dispositivo: seguido de El amigo y La iglesia y el Reino. Buenos Aires: Adriana Hidalgo Editora.

Botero, J. J. (2009). Fenomenología y ciencias cognitivas. Acta fenomenológica latinoamericana. III, 19-29.

Botero, J. J. (2010). Meaning, World and the Second Person. En S. Gallagher \& D. Schmicking (Eds.), Handbook of Phenomenology and Cognitive Science (pp. 355368). Dordrecht: Springer.

Deleuze, G. (1990). “¿Qué es un dispositivo?”. En Autor. Michel Foucault, filósofo (pp.155-163). Barcelona: Gedisa.

Deleuze, G., y Guattari, F. (1993). ¿Qué es filosofía? Barcelona: Anagrama.

Depraz, N. (2014). Attention et vigilance. A la croisée de la phénoménologie et des sciences cognitives. Paris: P.U.F.

Diógenes L. (1959). Vidas de los filósofos más ilustres. Madrid: Aguilar.

Fink, E. (1988). Cartesianische Meditation. Teil I: Die Idee einer transzendentalen Methodelehre. Netherlands: Kluwer Academic Publishers.

Foucault, M. (1974). Las palabras y las cosas. Una arqueología de las ciencias humanas. México: Siglo XXI.

Gallagher, S. (2006). How Body Shapes the Mind. Oxford: Oxford University Press.

Gendlin, E.T. (1978/79). Befindlichkeit: Heidegger and the Philosophy of Psychology. Review of Existential Psychology and Psychiatry, 16 (1-3), 43-71. 
Gil, L.M. (2016). Psicología, trabajo e individuación. Bogotá: San Pablo.

Gil, L.M. (2018). Psicología de la individuación. Bogotá: Aula de Humanidades.

Guerrero, M. J. (2017). La detrascendentalización de la ética en la valicepción: un estudio de Ideas II de Edmund Husserl. (Trabajo de grado, Licenciatura en Filosofía), Universidad Pedagógica Nacional, Bogotá.

Han, B.-C. (2012). La sociedad del cansancio. Barcelona: Herder.

Han, B.-C. (2015). Psicopolitica. Barcelona, Herder.

Hernández, S. (2018). ¿Es posible naturalizar la fenomenología? La naturalización de la psicología fenomenológica en sentido débil y la imposibilidad de la naturalización en sentido fuerte. (Trabajo de grado, Licenciatura en Filosofía). Universidad Pedagógica Nacional, Bogotá.

Hume, D. (1980). Investigación sobre el conocimiento humano (traducción Jaime de Salas Ortueta). Madrid: Alianza.

Hume, D. (1992). Investigación sobre el entendimiento humano. Bogotá: Norma.

Hume, D. (1993). An Enquiry Concerning Human Understanding. With A Letter from a Gentleman to his Friend in Edingburgh and Hume's Abstract of a Treatise of Human Nature. Indianápolis: Hackett.

Hume, D. (2011). Ensayos morales, politicos y literarios. Madrid: Trotta.

Husserl, E. (1976). Die Krisis der europäischen Wissenschaften und die transzendentale Phänomenologie. Eine Einleitung in die phänomenologische Philosophie. Hrsg. von Walter Biemel. Nachdruck der 2. verb. Auflage. (Hua. VI)

Husserl, E. (1969). Zur Phänomenologie des inneren Zeitbewusstesens (1893-1917). Noruega: Martinus Nijhoff. Hua. X

Husserl, E. (1987). El espíritu común (Gemeingeist) I y II Thémata: Revista de Filosofía, 4, 133-158.

Husserl, E. (1993). Die Krisis der europäischen Wissenschaften und die transzendentale Phänomenologie. Ergänzungsband. Texte aus dem Nachlass 1934-1937. Hrsg. von R.N. Smid. (Hua. XXIX).

Husserl, E. (2001). Die 'Bernauer Manuskripte’ über das Zeitbewußtsein (1917/18). Hua. XXXIII. Netherlands: Kluwer Academic Publishers.

Lazzarato, M. (2006). Trabajo autónomo, producción por medio del lenguaje y general intellect. Brumaria. Arte, máquinas, trabajo inmaterial, 7, 35-44. 
Lingins, A. (1983). Excesses: Eros and Culture. New York, Albany: SUNY Press.

Pentland, A. (2014). Social Physics. How Networks Can Make us Smarter. New York: Penguin Books.

Pinzón, I. N. (2017). La constitución del enemigo en la Alemania nazi. Revista de Psicologia Universidad de Antioquia, 9(2), 139-156.

Simondon, G. (2009). La individuación. A la luz de las nociones de forma y de información. Buenos Aires: La Cebra ediciones y editorial Cactus.

Vargas Guillén, G. (1999). El disponer. Folios, 11, 17-25.

Vargas Guillén, G. (2003a). La subjetividad y las perspectivas de la Inteligencia artificial. En Acta Fenomenológica Latinoamericana. Vol. I, Actas del II Coloquio Latinoamericano de Fenomenología. Círculo Latinoamericano de Fenomenología. (pp. 181-190). Lima: Universidad Católica del Perú.

Vargas Guillén, G. (2003b). La representación computacional de dilemas morales. Investigación fenomenológica de epistemología experimental. Bogotá: Universidad Pedagógica Nacional.

Vargas Guillén, G. (2004). Psicología y fenomenología trascendentales en el proyecto de la Inteligencia Artificial. Revista de Filosofía de la Universidad de Costa Rica, 42, 105-118.

Vargas Guillén, G. (2010). Mundo de la vida y fenomenología del lugar. Anuario Colombiano de Fenomenología, IV, 51-68.

Vargas Guillén, G. (2011a). La vía psicológica. La fenomenología y las ciencias de lo artificial. Anuario Colombiano de Fenomenología, V, 35-50.

Vargas Guillén, G. (2011b). Memoria y archivo. Entre fenomenología y hermenéutica. En Autor. Ausencia y presencia de Dios (pp. 83-107). Bogotá: San Pablo.

Vargas Guillén, G. (2012a). Formación y mundo de la vida. En Autor. Formación y mundo de la vida. Problemas teóricos y metodológicos de la fenomenología, Estudio IV (pp. 49-77). Saarbrücken: Editorial académica española.

Vargas Guillén, G. (2012b). La fenomenología y el ideal de la ciencia (En el centenario del artículo: La filosofía como ciencia rigurosa). Co-Herencia, 15, 69-87.

Vargas Guillén, G. (2014). Individuación y Anarquía. Bogotá: Aula de Humanidades.

Vargas Guillén, G. (2018). El análisis reflexivo y el método fenomenológico. Contribución a la detrascendentalización de la fenomenología. Investigaciones fenomenológicas, Vol. Monográfico 7, 237-255. 
Vargas Guillén, G., y Gil, L. M. (2013). Universidad e individuación. Fenomenología de la individuación y de la formación como transducción de información. En A. Ruiz (Comp.). Universidad e investigación (pp. 31-47). Medellín: Universidad Pontificia Bolivariana.

Vargas Guillén, G., y Gil, L. M. (2017). De la biopolitica a la psicopolítica. Un problema de frontera entre la filosofía y la psicología. Lección inaugural, Pregrado en Psicología, (UdeA), agosto 14 de 2017.

Vargas Guillén, G., y Gil, L. M. (2019). El problema de la constitución histórica del método. Enlace entre filosofía y psicología modernas. En P. Páramo (Ed.). Historia del método en las ciencias sociales: su historia y filosofía. Bogotá: Lemoine (en prensa).

Virno, P. (2003). Gramática de la multitud. Para un análisis de las formas de vida contemporáneas. Madrid: Traficantes de sueńos.

Virno, P. (2011). Ambivalencia de la multitud. Entre la innovación y la negatividad (Trad. Emilio Sadier y Diego Picotto.). Buenos Aires: Ed. Tinta Limón.

Zahavi, D. y Gallagher, S. (2014). La mente fenomenológica. Madrid: Alianza Editorial. 
